\title{
Medication Administered at Birth
}

National Cancer Institute

\section{Source}

National Cancer Institute. Medication Administered at Birth. NCI Thesaurus. Code C90603.

Pharmacologic agents administered to a neonate at birth. 